\title{
Lowering triglycerides to modify cardiovascular risk: will icosapent deliver?
}

\author{
This article was published in the following Dove Press journal: \\ Vascular Health and Risk Management \\ 25 March 2015 \\ Number of times this article has been viewed
}

\author{
Daniel J Scherer' \\ Stephen J Nicholls ${ }^{2}$ \\ 'Cardiovascular Investigation Unit, \\ Royal Adelaide Hospital, ${ }^{2}$ South \\ Australian Health and Medical \\ Research Institute, University of \\ Adelaide, Adelaide, SA, Australia
}

Correspondence: Stephen J Nicholls South Australian Health and Medical Research Institute, PO Box II060, Adelaide, SA 500I, Australia Tel +6I8 8I 2845 I0

Email stephen.nicholls@sahmri.com

\begin{abstract}
Despite the clinical benefits of lowering levels of low-density lipoprotein cholesterol, many patients continue to experience cardiovascular events. This residual risk suggests that additional risk factors require aggressive modification to result in more effective prevention of cardiovascular disease. Hypertriglyceridemia has presented a considerable challenge with regard to understanding its role in the promotion of cardiovascular risk. Increasing evidence has established a clear causal role for elevated triglyceride levels in vascular risk. As a result, there is increasing interest in the development of specific therapeutic strategies that directly target hypertriglyceridemia. This has seen a resurgence in the use of omega- 3 fatty acids for the therapeutic lowering of triglyceride levels. The role of these agents and other emerging strategies to reduce triglyceride levels in order to decrease vascular risk are reviewed.
\end{abstract}

Keywords: hypertriglyceridemia, omega-3 fatty acid, fish oil, cardiovascular risk, lipids

\section{Introduction}

The role of low-density lipoprotein cholesterol (LDL-C) in cardiovascular disease is well established, with LDL-C lowering being the cornerstone of preventive strategies. This is evidenced from statin trials, in which the degree of LDL-C lowering directly associated with their clinical benefit. ${ }^{1}$ However, many cardiovascular events continue to occur even in patients who achieve low LDL-C levels, reflecting a substantial residual risk. ${ }^{2}$ In the search to identify factors associated with persistent cardiovascular risk, it is clear that LDL-C alone does not fully reflect the circulating burden of atherogenic lipoproteins. In particular, triglyceride-rich particles (very low-density lipoproteins [VLDL], intermediate density lipoproteins, chylomicrons) play an important role in the promotion of the atherosclerotic disease process and are poorly reflected by conventional LDL-C measures. It is therefore not surprising that levels of non-high-density lipoprotein cholesterol (non-HDL-C), which reflect the entire burden of atherogenic lipid particles, associate with vascular risk and have become increasingly used as a secondary target for modification in treatment guidelines. ${ }^{3} \mathrm{As}$ the incidence of abdominal obesity, metabolic syndrome, and type 2 diabetes mellitus rises, associated triglyceride-rich lipoproteins are likely to have a greater impact on promoting vascular risk. ${ }^{4}$

\section{Population studies of hypertriglyceridemia and cardiovascular risk}

Elevated triglyceride levels have become increasingly prevalent in the community. Follow-up of the National Health and Nutrition Examination Survey has found that 
$32.2 \%$ of individuals have elevated triglyceride levels, including $1.7 \%$ with levels considered severe (500$2,000 \mathrm{mg} / \mathrm{dL}) .^{5}$ While early studies failed to convincingly establish an association between triglyceride levels and cardiovascular disease, more recent data, including cohort studies and meta-analyses, have shown that increases in both fasting and nonfasting triglyceride levels directly associate with cardiovascular risk.

Further analysis has revealed that the strength of the association between triglyceride levels and cardiovascular risk may differ between males and females, with evidence that each $1 \mathrm{mmol} / \mathrm{L}$ increase in triglyceride associates with a $32 \%$ and $76 \%$ increase in risk, respectively. While the degree of this association is attenuated after controlling for other metabolic risk factors, a greater impact in females continues to be observed. ${ }^{6}$ In clinical trials of statins, elevated triglyceride levels identify patients at a higher risk of cardiovascular events, despite use of high-intensity statin therapy. ${ }^{7}$

\section{Generation of triglyceride-rich lipoproteins}

Hypertriglyceridemia results from a number of sources, including dietary fat consumption and generation of chylomicron and remnant particles, hepatic synthesis of VLDL, and impaired metabolic clearance of these particles from the circulation. Triglyceride-rich lipoproteins undergo hydrolysis by lipoprotein lipase within capillary beds in adipose, cardiac, and skeletal muscle tissue beds to release nonesterified fatty acids for local use, generating remnant particles within the systemic circulation. These remnant particles, specifically VLDL remnants, contain substantial cholesterol due to increased activity of cholesteryl ester transfer protein in hypertriglyceridemia favoring transfer to VLDL rather than LDL particles. ${ }^{8}$ Reduced size of these remnant particles renders them more likely to enter and be retained within the artery wall. ${ }^{9,10}$ In this location, they play a significant role in formation of foam cells, the major cellular component of the evolving atherosclerotic plaque. ${ }^{11,12}$

Apolipoprotein C (apoC)-III resides on VLDL, LDL, chylomicrons, and HDL particles within the circulation. Increased apoC-III production is a characteristic feature of patients with insulin resistance and hypertriglyceridemia, by virtue of its role in the inhibition of lipolytic activity ${ }^{13}$ and hepatic uptake of triglyceride-rich lipoproteins. Increasing evidence implicates apoC-III in the promotion of inflammatory pathways within the artery wall, suggesting that it may influence atherogenesis via lipid-mediated and lipidindependent processes. ${ }^{14}$ Further evidence that these factors involved in the metabolism of triglyceride-rich lipoproteins play an important role in atherosclerosis comes from genomic and biomarker studies demonstrating their association with cardiovascular events. ${ }^{15-17}$

\section{Treatment of hypertriglyceridemia Lifestyle modification}

The initial effort to lower triglyceride levels should begin with lifestyle modification and improved glycemic control in diabetes, with evidence that these measures can have rapid and profound beneficial effects. Weight loss is associated with consistent reductions in triglyceride levels across multiple studies and is an essential part of treatment for hypertriglyceridemia. ${ }^{18-21}$ The relative impact of specific diets and exercise regimens on achieving weight loss has had variable reports with regard to their effects on triglyceride levels.

High-fat content diets lead to obesity and increased visceral adiposity, which is associated with insulin resistance. While a low-fat diet would intuitively seem the best dietary approach, there are some reports that comparisons of moderate-fat content diets with low-fat diets actually show that moderate fat intake elicits a more favorable effect on triglyceride levels. ${ }^{22}$ High-carbohydrate diets are associated with increased fatty liver changes, ${ }^{23}$ which are associated with increased hepatic triglyceride-rich lipoprotein production in proportion to the degree of liver fat. ${ }^{24}$ Low-carbohydrate diets consistently lower triglycerides, more so in those with higher baseline levels, ${ }^{25}$ and when integrated within Mediterranean diets appear to be superior in their triglyceride-lowering effect than low-fat diets. ${ }^{26}$

Exercise increases lipoprotein lipase activity ${ }^{27}$ with modest triglyceride lowering. ${ }^{28}$ While smoking cessation can often be associated with weight gain, its benefit in terms of triglyceride lowering is still evident, given the association of insulin resistance and postprandial hypertriglyceridemia in smokers. ${ }^{29}$ There appears to be a U-shaped relationship between amount of alcohol intake and triglyceride levels, so hypertriglyceridemic patients should be encouraged to only drink alcohol in moderation. ${ }^{30}$ For patients presenting with marked hypertriglyceridemia, cessation of alcohol consumption, restriction of dietary fat intake, and more aggressive glycemic control in diabetic patients can each have a rapid and profound effect on triglyceride levels.

\section{Statins}

Statins lower triglycerides in a dose-dependent manner, particularly in the hypertriglyceridemia patient. ${ }^{31,32}$ Given their 
benefit in terms of cardiovascular event rate reduction, treatment guidelines recommend intensification of LDL-C lowering with statins as the first pharmacological treatment choice in hypertriglyceridemic patients. The persistence of elevated triglyceride levels identifies patients with a residual clinical risk in statin trials, suggesting an ongoing need to develop additional therapeutic strategies for these patients.

\section{Fibrates}

Fibrates are modest pharmacological agonists of peroxisome proliferator-activated receptor- $\alpha$ (PPAR- $\alpha$ ), a transcription factor and major regulator of lipid metabolism. Their major influences on plasma lipids include reducing triglycerides and increasing HDL cholesterol. Their lipid effects appear to be mediated by a reduction in apoC-III expression and increases in lipoprotein lipase activity, hepatic synthesis of the major apolipoproteins (apoA-I, apoA-II) carried on HDL particles, and oxidation of fatty acids, which in turn lead to a decrease in the rate of hepatic lipogenesis. ${ }^{33}$ While studies have shown that fibrates retard progression of angiographic disease ${ }^{34,35}$ the major clinical outcome trials of fibrates have demonstrated variable effects on cardiovascular events. While studies of gemfibrozil have demonstrated a favorable effect, ${ }^{36,37}$ it can be difficult to administer in combination with statin therapy. More recent studies of fenofibrate in statintreated patients with diabetes failed to demonstrate a benefit in terms of the primary endpoint, ${ }^{38,39}$ although subsequent analyses have shown a favorable impact on hard clinical endpoints (death, myocardial infarction, stroke) ${ }^{39}$ in patients with a prior myocardial infarction ${ }^{40}$ and on the microvascular complications of diabetes. ${ }^{41}$ While triglyceride lowering does not appear to contribute to any potential benefit of fibrate therapy, meta-analyses have demonstrated that it is the patient with elevated triglyceride levels at baseline in whom they are most likely to be protective. ${ }^{42}$ Recent attempts to develop more potent PPAR- $\alpha^{43}$ and dual PPAR- $\alpha / \gamma$ agonists ${ }^{44}$ have failed to demonstrate incremental efficacy and have raised additional safety concerns.

\section{Niacin}

Niacin has a range of lipid-modifying effects, including substantial raising of HDL-C in addition to lowering of triglycerides, LDL-C, and lipoprotein(a). ${ }^{45}$ While the mechanism underlying its lipid effects remains to fully elucidated, triglyceride lowering is likely to result from inhibition of diacylglycerol acyltransferase $2 .{ }^{46}$ Early trials prior to the use of statins demonstrated reductions in cardiovascular events in survivors of myocardial infarction with immediate-release formulations of niacin administered as monotherapy ${ }^{47}$ and in combination with clofibrate. ${ }^{48}$ Subsequent arterial wall imaging studies have demonstrated that niacin has a favorable impact on progression of atherosclerotic disease within the coronary and carotid vasculature. ${ }^{49-52}$ However, niacin use is limited by near ubiquitous experience of flushing mediated by prostaglandin-mediated vasodilation. This prevents appropriate dose escalation required to achieve lipid effects. Multiple efforts have been undertaken to improve tolerance of niacin, including use of extended-release formulations and administration in combination with a selective prostaglandin-2 receptor inhibitor, laropiprant. However, clinical trials of these approaches in statin-treated patients have not demonstrated clinical efficacy, suggesting that niacin is not likely to be a widely used approach for lipid modification moving forward. ${ }^{53,54}$

\section{Omega-3 fatty acids in hypertriglyceridemia}

Considerable data, ranging from studies of fish consumption in populations through to supplementation studies have consistently demonstrated that omega-3 (n-3) fatty acids lower triglyceride levels by $10 \%-30 \%$ in patients with hypertriglyceridemia, depending on the amount of n-3 fatty acid administered and the baseline triglyceride level. ${ }^{55}$ The major n-3 fatty acids, eicasopentaenoic acid (EPA) and docasohexaenoic acid (DHA), modulate each of the major nuclear receptors that regulate triglyceride levels, including liver X receptor (LXR), farnesol X receptor (FXR), hepatocyte nuclear factor- $4 \alpha$, and PPAR $\alpha, \beta$, and $\gamma$.

These receptors play an important role in regulation of triglyceride-rich lipoproteins and therefore present a target for therapeutic modification by n-3 fatty acids. LXR regulates expression of sterol regulatory element-binding protein-1c (SREBP-1c), which plays a major role in transcription of fatty acid-synthesizing enzymes. The n-3 fatty acids inhibit LXR from binding to the LXR response element and reducing SREBP-1c transcription ${ }^{56}$ and act directly on SREBP-1c, inhibiting its maturation. ${ }^{57}$ FXR plays a regulatory role in the enterohepatic circulation of lipids, with it binding and being activated by several bile acids, with stimulation increasing expression of short heterodimer protein, which via heterodimerization has multiple effects on bile acid and triglyceride homeostasis, including reducing expression of cholesterol-7-hydroxylase, the enzyme that regulates cholesterol catabolism into bile acids, reducing transcription of SREBP-1c, upregulating expression of PPAR- $\alpha$, and decreasing hepatic secretion of 
triglyceride-containing lipoproteins. ${ }^{58,59}$ The n-3 fatty acids, via their FXR interaction, can differentially regulate expression of FXR targets. ${ }^{60}$ While n-3 fatty acids interact with all PPAR species, they have a clear preference for the $\alpha$-subtype ${ }^{61}$ decreasing triglycerides in a similar fashion to fibrates. Hepatocyte nuclear factor- $\alpha$ has multiple important roles in hepatic regulation of lipid metabolism, carbohydrate metabolism, hematopoiesis, and blood coagulation. It plays an important role in the regulation of hepatic expression of apolipoproteins (A-I, A-II, B, C-II, C-III) and microsomal transfer protein. n-3 fatty acid stimulation of hepatocyte nuclear factor- $\alpha$ leads to a reduction of apoC-III expression. ${ }^{62} \mathrm{EPA}$, but not DHA, inhibits activity of diacylglycerol acyltransferase, an enzyme that regulates the terminal and rate-limiting step of hepatic triglyceride synthesis. ${ }^{63}$ Accordingly, n-3 fatty acids play an important and diverse role in influencing a range of factors implicated in the regulation of triglyceride levels.

\section{Prescription $\mathbf{n - 3}$ fatty acid formulations}

A range of over-the-counter preparations of n-3 fatty acids, often under the label of fish oil, are widely used in population for a range of indications, including lowering of plasma triglyceride levels. However, the finding that large doses of EPA and DHA, in the range of 3-4 g daily, are often required to produce meaningful triglyceride lowering in hypertriglyceridemic patients, presents a challenge for the use of many of these preparations. The actual content of EPA and DHA in over-the-counter preparations is often low, requiring individuals to consume large numbers of capsules on a daily basis (often up to 12 daily) to achieve effective triglyceride lowering. Such findings have led to the production of pharmaceutical grade n-3 fatty acids with much higher concentrations ( $85 \%$ of their content were ethyl esters of EPA and DHA in comparison with most standard fish oil preparations containing 18\% EPA and 12\% DHA). ${ }^{64}$

The first prescription n-3 fatty acid preparation (Lovaza ${ }^{\circledR}$, initially marketed as Omacor $^{\circledR}$ ) approved for use as an adjunct to diet in the treatment of severe hypertriglyceridemia contained more than $90 \%$ of n-3 fatty acid ethyl esters (465 mg EPA, 375 mg DHA). Administration for up to 24 weeks in patients with severe hypertriglyceridemia demonstrated reductions in triglyceride levels by $19 \%-47 \%{ }^{65}$ In parallel, early observations of increases in LDL-C levels were reported, the extent of which depended on the baseline triglyceride level. ${ }^{66}$ It remains unknown whether this increase in LDL-C might have an adverse effect on the artery wall. It has been postulated by some that DHA plays a more prominent role in LDL-C elevation, with meta-analyses of both individual and comparative studies revealing increases in LDL-C in $75 \%$ of DHA-treated and $40 \%$ of EPA-treated patients. ${ }^{67}$ While the mechanism for the LDL-C increase remains to be fully elucidated, it has been proposed that this is likely to involve accelerated conversion of VLDL to intermediate density lipoprotein and LDL particles. ${ }^{68}$

\section{Icosapent}

Icosapent is the first EPA only prescription n-3 fatty acid (containing $96 \%$ of the ethyl ester of EPA) to receive regulatory approval. It undergoes de-esterification during intestinal absorption and enters the systemic circulation via the thoracic duct, achieving its peak plasma concentration 5 hours following ingestion. Icosapent is $>99 \%$ protein bound in the plasma, has a volume of distribution of 88 liters, and displays predictable linear pharmacokinetics. It is currently approved for use as an adjunct to diet to reduce triglyceride levels in adult patients with severe ( $\geq 500 \mathrm{mg} / \mathrm{dL}$ ) hypertriglyceridemia. There are ongoing studies assessing its efficacy in reducing the risk of cardiovascular events in high-risk patients with mixed dyslipidemia.

A multicenter, placebo-controlled, randomized, doubleblind 12-week study with an open-label extension (MARINE) ${ }^{69}$ was conducted in patients with very high triglyceride levels, with randomization to either $2 \mathrm{~g}$ or $4 \mathrm{~g}$ daily of icosapent or placebo for 12 weeks. The treatment period was preceded by a 4-6-week run-in period, where subjects were counseled on a lifestyle changes diet to comply with throughout the trial. Subjects with triglyceride levels of between $500 \mathrm{mg} / \mathrm{dL}$ and $2,000 \mathrm{mg} / \mathrm{dL}$ following the run-in period qualified for randomization. The major exclusion criteria included supermorbid obesity (body mass index $>45 \mathrm{~kg} / \mathrm{m}^{2}$ ), poorly controlled diabetes, uncontrolled thyroid disease, nephritic syndrome range proteinuria ( $>3 \mathrm{~g} /$ day), and heavy alcohol intake. Twenty-five percent of the subjects included in the randomization were treated with a statin. Significant placebo-adjusted reductions in triglycerides were observed in both the $4 \mathrm{~g}(-33.1 \%$, $P<0.0001)$ and $2 \mathrm{~g}(-19.7 \%, P=0.005)$ groups. In those individuals with baseline triglyceride levels $>750 \mathrm{mg} / \mathrm{dL}$, greater reductions were observed in the $4 \mathrm{~g}(-45.4 \%, P=0.0001)$ and $2 \mathrm{~g}(-32.9 \%, P=0.002)$ groups. Associated reductions in non-HDL-C, VLDL, and lipoprotein phospholipase A2 were also observed, with greater effects noted in the $4 \mathrm{~g}$ group. Significant LDL-C elevations were not observed in this study, although the exploratory analysis was underpowered. Icosapent was well tolerated, with similar rates of adverse events (most commonly nausea, diarrhea, and eructation) observed in both groups. 
The ANCHOR study ${ }^{70}$ was a randomized, double-blind, placebo-controlled study of patients with a high cardiovascular disease risk and adequate LDL-C control (40-115 mg/dL) with statins \pm ezetimibe, but with high triglyceride levels $(185-500 \mathrm{mg} / \mathrm{dL})$. A total of 702 patients were randomized to $2 \mathrm{~g}$ or $4 \mathrm{~g}$ of icosapent or placebo daily for a 12-week treatment period, following a run-in period similar to that of the MARINE study. The study included a prespecified analysis to demonstrate noninferiority of LDL-C change compared with placebo. The key exclusion criteria for the trial were supermorbid obese patients with a body mass index $>45 \mathrm{~kg} / \mathrm{m}^{2}$, poorly controlled diabetics, and subjects treated with fibrates or niacin. Significant reductions in triglyceride levels were observed in both the $4 \mathrm{~g}(-21.5 \%, P<0.0001)$ and $2 \mathrm{~g}$ $(-10.1 \%, P=0.0005)$ groups. Similar reductions in associated lipoproteins were observed as reported in MARINE, with the additional finding of a significant reduction in C-reactive protein in the $4 \mathrm{~g}$ group. Noninferiority compared with placebo with regards to LDL-C changes was observed in both active treatment groups. Icosapent was well tolerated, with similar adverse event and discontinuation rates reported in all three treatment groups.

\section{Outcome trials with EPA}

JELIS (the Japan EPA Lipid Intervention Study) was a prospective, randomized, open-label, blinded endpoint trial of 18,645 patients with elevated serum total cholesterol ( $\geq 250 \mathrm{mg} / \mathrm{dL}$ ), but notably relatively normal triglyceride levels, treated with EPA $1.8 \mathrm{~g}$ or placebo daily in addition to statin therapy. Treatment with EPA was associated with a greater lowering of triglycerides ( $-9 \%$ versus $-4 \%, P<0.0001)$ and a $19 \%$ reduction in the composite primary endpoint of any major coronary event, including sudden cardiac death, fatal or nonfatal myocardial infarction and nonfatal events, unstable angina pectoris, or need for coronary revascularization. Subsequent analyses revealed that EPA reduced cardiovascular events by $53 \%$ in patients with evidence of atherogenic dyslipidemia at baseline (triglycerides $>150 \mathrm{mg} / \mathrm{dL}, \mathrm{HDL}-\mathrm{C}<40 \mathrm{mg} / \mathrm{dL}$ ). ${ }^{71,72}$ Of particular interest, these findings were observed in a study performed exclusively in Japan, where the doses of background statin therapy were low, the dose of EPA was relatively modest, and general consumption of fish is higher. Accordingly, it is of interest to know whether similar findings could be observed in Western populations.

\section{REDUCE-IT}

REDUCE-IT is a multicenter, multinational, prospective, randomized, double-blind, placebo-controlled, parallel-group study of patients aged $\geq 45$ years and at high risk for cardiovascular events, with elevated triglyceride levels (150-500 mg/dL) despite optimized statin therapy. Subjects will be randomized to treatment with icosapent $4 \mathrm{~g}$ or placebo daily. Treatment groups will be compared with regard to the incidence of cardiovascular death, nonfatal myocardial infarction, nonfatal stroke, coronary revascularization, and unstable angina determined to be caused by myocardial ischemia on invasive or noninvasive testing and requiring emergent hospitalization. This will determine whether high-dose administration of EPA has a cardiovascular benefit in high-risk statin-treated patients with modest hypertriglyceridemia.

\section{Conclusion}

Hypertriglyceridemia at severe levels is an important risk factor for pancreatitis, and persistently high triglyceride levels despite optimal LDL-C control conveys increased residual risk of cardiovascular disease. There is a clear need for a therapeutic option in hypertriglyceridemia that can be used in addition to statin therapy to further reduce the cardiovascular disease risk and burden. Icosapent shows clear benefit in the treatment of severe hypertriglyceridemia and has also shown efficacy in the treatment of patients with more moderate elevations in serum triglyceride levels already treated with statins. However, favorable effects on lipid biomarkers, particularly those beyond LDL-C, have not been easily demonstrated to translate to a beneficial effect on cardiovascular events. Accordingly, the result of REDUCE-IT will be eagerly awaited to determine whether icosapent will be widely used or remain as a treatment for severe hypertriglyceridemia alone.

\section{Disclosure}

The authors report no conflicts of interest in this work.

\section{References}

1. Baigent C, Blackwell L, Emberson J, et al. Efficacy and safety of more intensive lowering of LDL cholesterol: a meta-analysis of data from 170,000 participants in 26 randomised trials. Lancet. 2010;376: 1670-1681.

2. Libby P. The forgotten majority: unfinished business in cardiovascular risk reduction. J Am Coll Cardiol. 2005;46:1225-1228.

3. Robinson JG, Wang S, Smith BJ, Jacobson TA. Meta-analysis of the relationship between non-high-density lipoprotein cholesterol reduction and coronary heart disease risk. J Am Coll Cardiol. 2009;53:316-322.

4. Ascaso JF, Millan J, Mateo-Gallego R, et al. Prevalence of metabolic syndrome and cardiovascular disease in a hypertriglyceridemic population. Eur J Intern Med. 2011;22:177-181.

5. Christian JB, Bourgeois N, Snipes R, Lowe KA. Prevalence of severe ( 500 to $2,000 \mathrm{mg} / \mathrm{dl}$ ) hypertriglyceridemia in United States adults. Am J Cardiol. 2011;107:891-897.

6. Austin MA, Hokanson JE, Edwards KL. Hypertriglyceridemia as a cardiovascular risk factor. Am J Cardiol. 1998;81:7B-12B. 
7. Bansal S, Buring JE, Rifai N, Mora S, Sacks FM, Ridker PM. Fasting compared with nonfasting triglycerides and risk of cardiovascular events in women. JAMA. 2007;298:309-316.

8. Guerin M, Le Goff W, Lassel TS, Van Tol A, Steiner G, Chapman MJ. Atherogenic role of elevated CE transfer from HDL to VLDL(1) and dense LDL in type 2 diabetes: impact of the degree of triglyceridemia. Arterioscler Thromb Vasc Biol. 2001;21:282-288.

9. Proctor SD, Vine DF, Mamo JC. Arterial permeability and efflux of apolipoprotein B-containing lipoproteins assessed by in situ perfusion and three-dimensional quantitative confocal microscopy. Arterioscler Thromb Vasc Biol. 2004;24:2162-2167.

10. Nordestgaard BG, Wootton R, Lewis B. Selective retention of VLDL, IDL, and LDL in the arterial intima of genetically hyperlipidemic rabbits in vivo. Molecular size as a determinant of fractional loss from the intima-inner media. Arterioscler Thromb Vasc Biol. 1995;15:534-542.

11. Tanaka A, Ai M, Kobayashi Y, Tamura M, Shimokado K, Numano F. Metabolism of triglyceride-rich lipoproteins and their role in atherosclerosis. Ann N Y Acad Sci. 2001;947:207-212.

12. Nordestgaard BG, Nielsen LB. Atherosclerosis and arterial influx of lipoproteins. Curr Opin Lipidol. 1994;5:252-257.

13. Wang CS, McConathy WJ, Kloer HU, Alaupovic P. Modulation of lipoprotein lipase activity by apolipoproteins. Effect of apolipoprotein C-III. J Clin Invest. 1985;75:384-390.

14. Bobik A. Apolipoprotein CIII and atherosclerosis: beyond effects on lipid metabolism. Circulation. 2008;118:702-704.

15. Thomsen M, Varbo A, Tybjaerg-Hansen A, Nordestgaard BG. Low nonfasting triglycerides and reduced all-cause mortality: a mendelian randomization study. Clin Chem. 2014;60:737-746.

16. Varbo A, Benn M, Tybjaerg-Hansen A, Nordestgaard BG. Elevated remnant cholesterol causes both low-grade inflammation and ischemic heart disease, whereas elevated low-density lipoprotein cholesterol causes ischemic heart disease without inflammation. Circulation. 2013;128:1298-1309.

17. Zheng C. Updates on apolipoprotein CIII: fulfilling promise as a therapeutic target for hypertriglyceridemia and cardiovascular disease. Curr Opin Lipidol. 2014;25:35-39.

18. Jalkanen $\mathrm{L}$. The effect of a weight reduction program on cardiovascular risk factors among overweight hypertensives in primary health care. Scand J Soc Med. 1991;19:66-71.

19. Krauss RM, Blanche PJ, Rawlings RS, Fernstrom HS, Williams PT. Separate effects of reduced carbohydrate intake and weight loss on atherogenic dyslipidemia. Am J Clin Nutr. 2006;83:1025-1031.

20. Gardner CD, Kiazand A, Alhassan S, et al. Comparison of the Atkins, Zone, Ornish, and LEARN diets for change in weight and related risk factors among overweight premenopausal women: the A TO Z Weight Loss Study: a randomized trial. JAMA. 2007;297:969-977.

21. Purnell JQ, Kahn SE, Albers JJ, Nevin DN, Brunzell JD, Schwartz RS. Effect of weight loss with reduction of intra-abdominal fat on lipid metabolism in older men. J Clin Endocrinol Metab. 2000;85: 977-982.

22. Cao Y, Mauger DT, Pelkman CL, Zhao G, Townsend SM, KrisEtherton PM. Effects of moderate (MF) versus lower fat (LF) diets on lipids and lipoproteins: a meta-analysis of clinical trials in subjects with and without diabetes. J Clin Lipidol. 2009;3:19-32.

23. Sevastianova K, Santos A, Kotronen A, et al. Effect of short-term carbohydrate overfeeding and long-term weight loss on liver fat in overweight humans. Am J Clin Nutr. 2012;96:727-734.

24. Westerbacka J, Kotronen A, Fielding BA, et al. Splanchnic balance of free fatty acids, endocannabinoids, and lipids in subjects with nonalcoholic fatty liver disease. Gastroenterology. 2010;139:1961-1971. e1.

25. Volek JS, Sharman MJ, Forsythe CE. Modification of lipoproteins by very low-carbohydrate diets. $J$ Nutr. 2005;135:1339-1342.

26. Shai I, Schwarzfuchs D, Henkin Y, et al. Weight loss with a lowcarbohydrate, Mediterranean, or low-fat diet. $N$ Engl J Med. 2008;359:229-241.

27. Seip RL, Mair K, Cole TG, Semenkovich CF. Induction of human skeletal muscle lipoprotein lipase gene expression by short-term exercise is transient. Am J Physiol. 1997;272:E255-E261.
28. Carroll S, Dudfield M. What is the relationship between exercise and metabolic abnormalities? A review of the metabolic syndrome. Sports Med. 2004:34:371-418.

29. Eliasson B, Mero N, Taskinen MR, Smith U. The insulin resistance syndrome and postprandial lipid intolerance in smokers. Atherosclerosis. 1997;129:79-88.

30. Brinton EA. Effects of ethanol intake on lipoproteins and atherosclerosis. Curr Opin Lipidol. 2010;21:346-351.

31. Bakker-Arkema RG, Davidson MH, Goldstein RJ, et al. Efficacy and safety of a new HMG-CoA reductase inhibitor, atorvastatin, in patients with hypertriglyceridemia. JAMA. 1996;275:128-133.

32. Stein EA, Lane M, Laskarzewski P. Comparison of statins in hypertriglyceridemia. Am J Cardiol. 1998;81:66B-69B.

33. Staels B, Dallongeville J, Auwerx J, Schoonjans K, Leitersdorf E, Fruchart JC. Mechanism of action of fibrates on lipid and lipoprotein metabolism. Circulation. 1998;98:2088-2093.

34. Frick MH, Syvanne M, Nieminen MS, et al. Prevention of the angiographic progression of coronary and vein-graft atherosclerosis by gemfibrozil after coronary bypass surgery in men with low levels of HDL cholesterol. Lopid Coronary Angiography Trial (LOCAT) Study Group. Circulation. 1997;96:2137-2143.

35. [No authors listed]. Effect of fenofibrate on progression of coronaryartery disease in type 2 diabetes: the Diabetes Atherosclerosis Intervention Study, a randomised study. Lancet. 2001;357:905-910.

36. Manninen V, Elo MO, Frick MH, et al. Lipid alterations and decline in the incidence of coronary heart disease in the Helsinki Heart Study. JAMA. 1988;260:641-651.

37. Rubins HB, Robins SJ, Collins D, et al. Gemfibrozil for the secondary prevention of coronary heart disease in men with low levels of high-density lipoprotein cholesterol. Veterans Affairs High-Density Lipoprotein Cholesterol Intervention Trial Study Group. N Engl J Med. 1999;341:410-418.

38. Ginsberg HN, Elam MB, Lovato LC, et al. Effects of combination lipid therapy in type 2 diabetes mellitus. $N$ Engl J Med. 2010;362: $1563-1574$

39. Keech A, Simes RJ, Barter P, et al. Effects of long-term fenofibrate therapy on cardiovascular events in 9795 people with type 2 diabetes mellitus (the FIELD study): randomised controlled trial. Lancet. 2005;366:1849-1861.

40. Tonkin A, Hunt D, Voysey M, et al. Effects of fenofibrate on cardiovascular events in patients with diabetes, with and without prior cardiovascular disease: the Fenofibrate Intervention and Event Lowering in Diabetes (FIELD) study. Am Heart J. 2012;163:508-514.

41. Keech AC, Mitchell P, Summanen PA, et al. Effect of fenofibrate on the need for laser treatment for diabetic retinopathy (FIELD study): a randomised controlled trial. Lancet. 2007;370:1687-1697.

42. Jun M, Foote C, Lv J, et al. Effects of fibrates on cardiovascular outcomes: a systematic review and meta-analysis. Lancet. 2010;375:1875-1884.

43. Nissen SE, Nicholls SJ, Wolski K, et al. Effects of a potent and selective PPAR-alpha agonist in patients with atherogenic dyslipidemia or hypercholesterolemia: two randomized controlled trials. JAMA. 2007;297:1362-1373.

44. Lincoff AM, Tardif JC, Schwartz GG, et al. Effect of aleglitazar on cardiovascular outcomes after acute coronary syndrome in patients with type 2 diabetes mellitus: the AleCardio randomized clinical trial. JAMA. 2014;311:1515-1525.

45. Carlson LA, Hamsten A, Asplund A. Pronounced lowering of serum levels of lipoprotein $\mathrm{Lp}(\mathrm{a})$ in hyperlipidaemic subjects treated with nicotinic acid. J Intern Med. 1989;226:271-276.

46. Ganji SH, Tavintharan S, Zhu D, Xing Y, Kamanna VS, Kashyap ML. Niacin noncompetitively inhibits DGAT2 but not DGAT1 activity in HepG2 cells. J Lipid Res. 2004;45:1835-1845.

47. [No authors listed]. Clofibrate and niacin in coronary heart disease. JAMA. 1975;231:360-381.

48. Carlson LA, Rosenhamer G. Reduction of mortality in the Stockholm Ischaemic Heart Disease Secondary Prevention Study by combined treatment with clofibrate and nicotinic acid. Acta Med Scand. 1988;223:405-418. 
49. Brown BG, Zhao XQ, Chait A, et al. Simvastatin and niacin, antioxidant vitamins, or the combination for the prevention of coronary disease. N Engl J Med. 2001;345:1583-1592.

50. Taylor AJ, Sullenberger LE, Lee HJ, Lee JK, Grace KA. Arterial Biology for the Investigation of the Treatment Effects of Reducing Cholesterol (ARBITER) 2: a double-blind, placebo-controlled study of extendedrelease niacin on atherosclerosis progression in secondary prevention patients treated with statins. Circulation. 2004;110:3512-3517.

51. Taylor AJ, Lee HJ, Sullenberger LE. The effect of 24 months of combination statin and extended-release niacin on carotid intima-media thickness: ARBITER 3. Curr Med Res Opin. 2006;22:2243-2250.

52. Sibley CT, Vavere AL, Gottlieb I, et al. MRI-measured regression of carotid atherosclerosis induced by statins with and without niacin in a randomised controlled trial: the NIA plaque study. Heart. 2013;99: 1675-1680.

53. Boden WE, Probstfield JL, Anderson T, et al. Niacin in patients with low HDL cholesterol levels receiving intensive statin therapy. $N$ Engl J Med. 2011;365:2255-2267.

54. Landray MJ, Haynes R, Hopewell JC, et al. Effects of extendedrelease niacin with laropiprant in high-risk patients. $N$ Engl J Med. 2014;371:203-212.

55. Harris WS. Fish oils and plasma lipid and lipoprotein metabolism in humans: a critical review. J Lipid Res. 1989;30:785-807.

56. Ou J, Tu H, Shan B, et al. Unsaturated fatty acids inhibit transcription of the sterol regulatory element-binding protein-1c (SREBP-1c) gene by antagonizing ligand-dependent activation of the LXR. Proc Natl Acad Sci U S A. 2001;98:6027-6032.

57. Hannah VC, Ou J, Luong A, Goldstein JL, Brown MS. Unsaturated fatty acids down-regulate srebp isoforms $1 \mathrm{a}$ and $1 \mathrm{c}$ by two mechanisms in HEK-293 cells. J Biol Chem. 2001;276:4365-4372.

58. Bilz S, Samuel V, Morino K, Savage D, Choi CS, Shulman GI. Activation of the farnesoid $\mathrm{X}$ receptor improves lipid metabolism in combined hyperlipidemic hamsters. Am J Physiol Endocrinol Metab. 2006;290:E716-E722.

59. Watanabe M, Houten SM, Wang L, et al. Bile acids lower triglyceride levels via a pathway involving FXR, SHP, and SREBP-1c. J Clin Invest. 2004;113:1408-1418.

60. Zhao A, Yu J, Lew JL, Huang L, Wright SD, Cui J. Polyunsaturated fatty acids are FXR ligands and differentially regulate expression of FXR targets. DNA Cell Biol. 2004;23:519-526.

61. Krey G, Braissant O, L'Horset F, et al. Fatty acids, eicosanoids, and hypolipidemic agents identified as ligands of peroxisome proliferatoractivated receptors by coactivator-dependent receptor ligand assay. Mol Endocrinol. 1997;11:779-791.
62. Hertz R, Sheena V, Kalderon B, Berman I, Bar-Tana J. Suppression of hepatocyte nuclear factor-4alpha by acyl-CoA thioesters of hypolipidemic peroxisome proliferators. Biochem Pharmacol. 2001;61: 1057-1062.

63. Berge RK, Madsen L, Vaagenes H, Tronstad KJ, Gottlicher M, Rustan AC. In contrast with docosahexaenoic acid, eicosapentaenoic acid and hypolipidaemic derivatives decrease hepatic synthesis and secretion of triacylglycerol by decreased diacylglycerol acyltransferase activity and stimulation of fatty acid oxidation. Biochem J. 1999;343 Pt 1: 191-197.

64. Skulas-Ray AC, West SG, Davidson MH, Kris-Etherton PM. Omega-3 fatty acid concentrates in the treatment of moderate hypertriglyceridemia. Expert Opin Pharmacother. 2008;9:1237-1248.

65. Bays H. Clinical overview of Omacor: a concentrated formulation of omega-3 polyunsaturated fatty acids. Am J Cardiol. 2006;98:71i-76i.

66. Westphal S, Orth M, Ambrosch A, Osmundsen K, Luley C. Postprandial chylomicrons and VLDLs in severe hypertriacylglycerolemia are lowered more effectively than are chylomicron remnants after treatment with n-3 fatty acids. Am J Clin Nutr. 2000;71:914-920.

67. Jacobson TA, Glickstein SB, Rowe JD, Soni PN. Effects of eicosapentaenoic acid and docosahexaenoic acid on low-density lipoprotein cholesterol and other lipids: a review. J Clin Lipidol. 2012;6:5-18.

68. Chan DC, Watts GF, Barrett PH, Beilin LJ, Redgrave TG, Mori TA. Regulatory effects of HMG CoA reductase inhibitor and fish oils on apolipoprotein B-100 kinetics in insulin-resistant obese male subjects with dyslipidemia. Diabetes. 2002;51:2377-2386.

69. Bays HE, Ballantyne CM, Kastelein JJ, Isaacsohn JL, Braeckman RA, Soni PN. Eicosapentaenoic acid ethyl ester (AMR101) therapy in patients with very high triglyceride levels (from the Multicenter, plAcebo-controlled, Randomized, double-bliNd, 12-week study with an open-label Extension [MARINE] trial). Am J Cardiol. 2011;108: 682-690.

70. Ballantyne CM, Bays HE, Kastelein JJ, et al. Efficacy and safety of eicosapentaenoic acid ethyl ester (AMR101) therapy in statin-treated patients with persistent high triglycerides (from the ANCHOR study). Am J Cardiol. 2012;110:984-992.

71. Yokoyama M, Origasa H, Matsuzaki M, et al. Effects of eicosapentaenoic acid on major coronary events in hypercholesterolaemic patients (JELIS): a randomised open-label, blinded endpoint analysis. Lancet. 2007;369:1090-1098.

72. Saito Y, Yokoyama M, Origasa H, et al. Effects of EPA on coronary artery disease in hypercholesterolemic patients with multiple risk factors: sub-analysis of primary prevention cases from the Japan EPA Lipid Intervention Study (JELIS). Atherosclerosis. 2008;200:135-140.
Vascular Health and Risk Management

\section{Publish your work in this journal}

Vascular Health and Risk Management is an international, peerreviewed journal of therapeutics and risk management, focusing on concise rapid reporting of clinical studies on the processes involved in the maintenance of vascular health; the monitoring, prevention and treatment of vascular disease and its sequelae; and the involvement of

\section{Dovepress}

metabolic disorders, particularly diabetes. This journal is indexed on PubMed Central and MedLine. The manuscript management system is completely online and includes a very quick and fair peer-review system, which is all easy to use. Visit http://www.dovepress.com/ testimonials.php to read real quotes from published authors. 